\title{
Reduced carbon emission estimates from fossil fuel combustion and cement production in China
}

\author{
Zhu Liu ${ }^{1,2,3}$, Dabo Guan ${ }^{4,5}$, Wei Wei ${ }^{6}$, Steven J. Davis ${ }^{2,7}$, Philippe Ciais ${ }^{8}$, Jin Bai ${ }^{9}$, Shushi Peng ${ }^{8,10}$, Qiang Zhang ${ }^{4}$, \\ Klaus Hubacek ${ }^{11}$, Gregg Marland ${ }^{12}$, Robert J. Andres ${ }^{13}$, Douglas Crawford-Brown ${ }^{14}$, Jintai Lin ${ }^{15}$, Hongyan Zhao , \\ Chaopeng Hong ${ }^{4,16}$, Thomas A. Boden ${ }^{13}$, Kuishuang Feng ${ }^{11}$, Glen P. Peters ${ }^{17}$, Fengming Xi ${ }^{211}$, Junguo Liu ${ }^{19,20,21}$, \\ Yuan $\mathrm{Li}^{5}$, Yu Zhao ${ }^{22}$, Ning Zeng ${ }^{23,24} \&$ Kebin $\mathrm{He}^{16}$
}

Nearly three-quarters of the growth in global carbon emissions from the burning of fossil fuels and cement production between 2010 and 2012 occurred in China ${ }^{1,2}$. Yet estimates of Chinese emissions remain subject to large uncertainty; inventories of China's total fossil fuel carbon emissions in 2008 differ by 0.3 gigatonnes of carbon, or 15 per cent ${ }^{1,3-5}$. The primary sources of this uncertainty are conflicting estimates of energy consumption and emission factors, the latter being uncertain because of very few actual measurements representative of the mix of Chinese fuels. Here we re-evaluate China's carbon emissions using updated and harmonized energy consumption and clinker production data and two new and comprehensive sets of measured emission factors for Chinese coal. We find that total energy consumption in China was 10 per cent higher in 2000-2012 than the value reported by China's national statistics ${ }^{6}$, that emission factors for Chinese coal are on average 40 per cent lower than the default values recommended by the Intergovernmental Panel on Climate Change ${ }^{7}$, and that emissions from China's cement production are 45 per cent less than recent estimates ${ }^{1,4}$. Altogether, our revised estimate of China's $\mathrm{CO}_{2}$ emissions from fossil fuel combustion and cement production is 2.49 gigatonnes of carbon ( 2 standard deviations $= \pm 7.3$ per cent) in 2013, which is 14 per cent lower than the emissions reported by other prominent inventories ${ }^{1,4,8}$. Over the full period 2000 to 2013, our revised estimates are 2.9 gigatonnes of carbon less than previous estimates of China's cumulative carbon emissions $^{1,4}$. Our findings suggest that overestimation of China's emissions in 2000-2013 may be larger than China's estimated total forest sink in 1990-2007 (2.66 gigatonnes of carbon) ${ }^{9}$ or China's land carbon sink in 2000-2009 (2.6 gigatonnes of carbon) ${ }^{10}$.

Reports of national carbon emissions $\mathrm{s}^{7,11-14}$ are based on activity data (that is, amounts of fuels burned) and emission factors (that is, amount of carbon oxidized per unit of fuel consumed), with these factors estimated as the product of the net carbon content (that is, tonnes carbon per joule), net heating value (that is, joules per tonne fuel), total carbon content (that is, tonnes carbon per tonne fuel) and oxidation rate (that is, carbon oxidized per carbon content; see Methods). The uncertainty of China's emissions estimates is typically reported as $\pm 5 \%$ to $\pm 10 \%$ (refs $4,13,15$ ), but this range is somewhat arbitrary because neither the activity data nor the accuracy of emission factors is well known. For instance, national activity data are substantially different from the sum of provincial activity data ${ }^{16}$, and the emissions factors used are not based on up-to-date measurements of the fuels actually being burned in China, of which the quality and mix are known to vary widely from

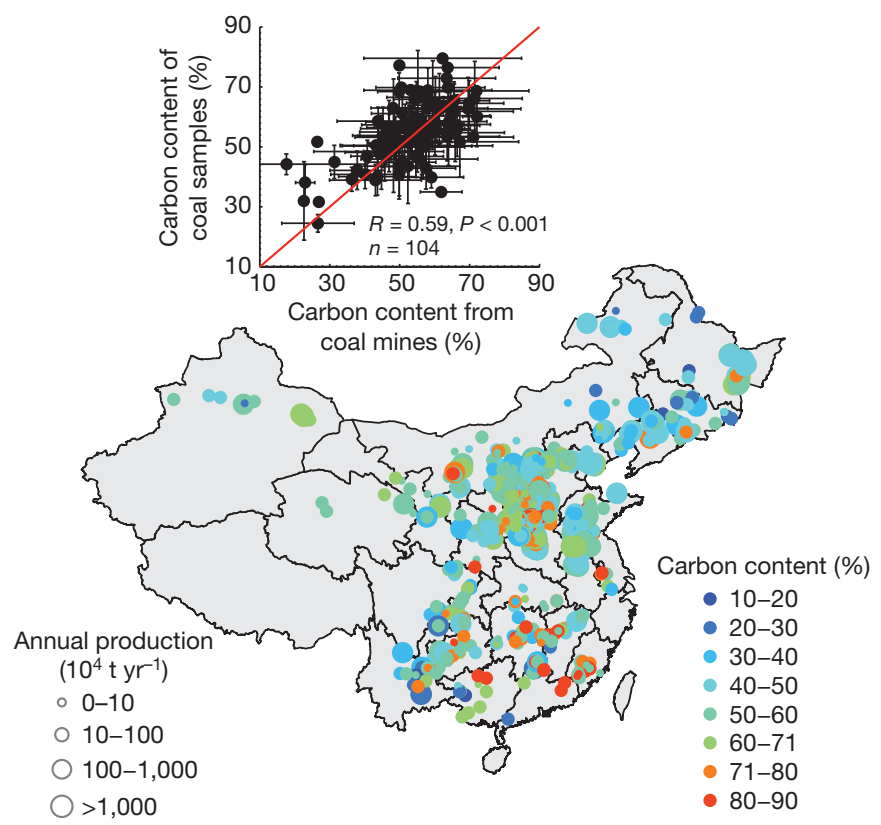

Figure $1 \mid$ Total carbon content and production of coal mines. The inset shows the comparison between carbon content from 602 coal samples and 4,243 coal mines $(R=0.59, P<0.001, n=104)$. Each dot in the inset indicates the average of carbon content from 602 coal samples and 4,243 coal mines in the same $1^{\circ}$ by $1^{\circ}$ grid. The nearly one-to-one correlation indicates that samples and mines capture the same spatial variability of coal carbon content across China.

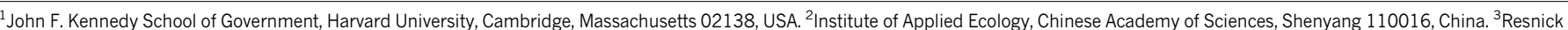
Sustainability Institute, California Institute of Technology, Pasadena, California 91125, USA. ${ }^{4}$ Ministry of Education Key Laboratory for Earth System Modeling, Center for Earth System Science, Tsinghua University, Beijing 100084, China. ${ }^{5}$ School of International Development, University of East Anglia, Norwich NR4 7TJ, UK. ${ }^{6}$ CAS Key Laboratory of Low-carbon Conversion Science and

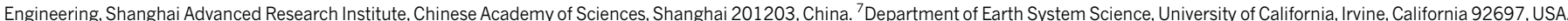

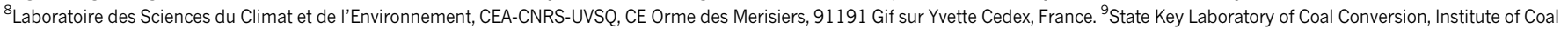

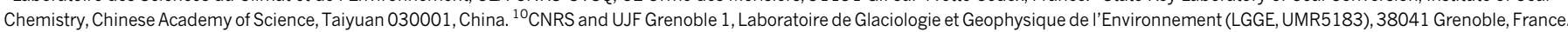
${ }^{11}$ Department of Geographical Sciences, University of Maryland, College Park, Maryland 20742, USA. ${ }^{12}$ Research Institute for Environment, Energy, and Economics, Appalachian State University,

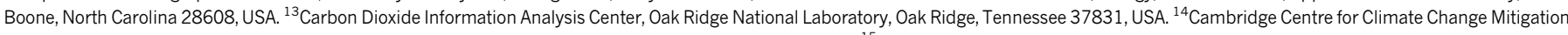
Research, Department of Land Economy, University of Cambridge, 19 Silver Street, Cambridge CB3 9EP, UK. ${ }^{15}$ Laboratory for Climate and Ocean-Atmosphere Studies, Department of Atmospheric and Oceanic Sciences, School of Physics, Peking University, Beijing 100871, China. ${ }^{16}$ State Key Joint Laboratory of Environment Simulation and Pollution Control, School of Environment, Tsinghua

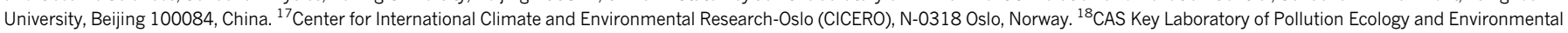

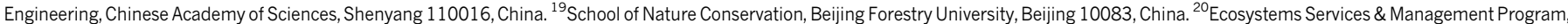
International Institute for Applied Systems Analysis, Schlossplatz 1, A-2361 Laxenburg, Austria. ${ }^{21}$ School of Environmental Science and Engineering, South University of Science and Technology

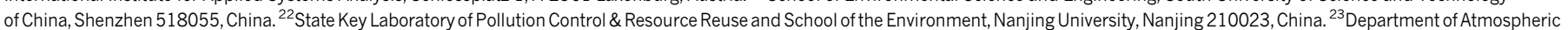
and Oceanic Science and Earth System Science Interdisciplinary Center, University of Maryland, College Park, Maryland 20742-2425, USA. ${ }^{24}$ Institute of Atmospheric Physics, Chinese Academy of Sciences, Beijing, 100029, China.
} 
year to year, especially for coal ${ }^{17}$. Indeed, using different official sources of activity data and emissions factors can result in estimated emissions that vary by up to $40 \%$ in a given year (see Methods).

Here, we present revised estimates of Chinese carbon emissions from the burning of fossil fuels and cement production during the period 1950-2013 using independently assessed activity data and two sets of comprehensive new measurements of emission factors. Results suggest that Chinese $\mathrm{CO}_{2}$ emissions have been substantially overestimated in recent years: $14 \%$ less than the estimates by the Emissions Database for Global Atmospheric Research (EDGAR) version 4.2 (EDGAR being adopted by the Intergovernmental Panel on Climate Change (IPCC) as the emission baseline) in 2013 and $12 \%$ less than the latest inventory China reported to the United Nations Framework Convention on Climate Change (UNFCCC; in 2005). The difference is due primarily to the emission factors used to estimate emissions from coal combustion; our measurements indicate that the factors applicable to Chinese coal are on average about $40 \%$ lower than the default values recommended by the IPCC ${ }^{7,11}$ and used by previous emissions inventories ${ }^{1,4,18}$.

In re-evaluating Chinese energy consumption, we adopt the 'apparent consumption' approach ${ }^{13,15}$, which does not depend upon energy consumption data (that previous studies have shown to be not very reliable $\left.{ }^{16,19}\right)$. Instead, apparent energy consumption is calculated from a mass balance of domestic fuel production, international trade, international fuelling, and changes in stocks, data about which are less subject to 'adjustment' by reporting bodies and accounting errors related to either energy consumed during fuel processing or assumptions about the mix of fuel types (especially coal) being used by individual consumers. Furthermore, this approach allows imported and domestically produced fuels to be tracked separately so that appropriate emission factors can be applied to these fuels (see Methods).

Apparent consumption of coal, oil and natural gas in China in 2013 was $3.84 \mathrm{Gt}$, $401.16 \mathrm{Mt}$ and $131.30 \mathrm{Gm}^{3}$, respectively. Between 1997 and 2012 , we estimate that cumulative energy consumption was $10 \%$ greater than the national statistics and 4\% lower than provincial statistics (Extended Data Fig. 2). In addition, our results indicate a higher annual growth rate of energy consumption than national statistics between 2000 and $2010\left(9.9 \% \mathrm{yr}^{-1}\right.$ instead of $\left.8.8 \% \mathrm{yr}^{-1}\right)$; the high growth rate is consistent with satellite observations of $\mathrm{NO}_{x}{ }^{20,21}$, although $\mathrm{NO}_{x}$ to fuel emission factors change with time as well.

Given the large fraction of $\mathrm{CO}_{2}$ emissions from coal combustion ( $80 \%$ between 2000 and 2013), estimates of total emissions are heavily dependent on the emission factors used to assess coal emissions. Thus, we re-evaluate each of the variables that determine these emission factors. The mean total carbon content of raw coal samples from 4,243 state-owned Chinese coal mines (4,243 mines represent 36\% of Chinese coal production in 2011) 22 (Fig. 1) is $58.45 \%$ (Fig. 2a), and the production-weighted total carbon content is $53.34 \%$.

These results straddle the results of an independent set of 602 coal samples from the 100 largest coal-mining areas in China (these areas together represent $99 \%$ of Chinese coal production in 2011) ${ }^{22}$ (Extended Data Fig. 3), which reveal a similarly low mean carbon content of $55.48 \%$ (Fig. 2b) and a production-weighted mean total carbon content of $54.21 \%$. The net carbon content per energy produced of these same samples is $26.59 \mathrm{tC} \mathrm{TJ}^{-1}$, or $26.32 \mathrm{tC} \mathrm{TJ}^{-1}$ if weighted by production (Fig. 2c), and their net heating value is 20.95 $\mathrm{PJ} \mathrm{Mt}^{-1}$, or 20.6 PJ Mt ${ }^{-1}$ if weighted by production (Fig. 2d). Although the measured net carbon content per energy produced of these samples is within $2 \%$ of the IPCC default value $\left(25.8 \mathrm{tC} \mathrm{TJ}^{-1}\right)$, the heating value from these coal samples (20.95 PJ Mt ${ }^{-1}$ ) is significantly less than either the IPCC default value (coking coal) of $28.2 \mathrm{PJ} \mathrm{Mt}^{-1}$ or the mean value of US coal of $26.81 \mathrm{PJ} \mathrm{Mt}^{-1}$ (ref. 23). The lower heating value of Chinese coal reflects its generally low quality and high ash content (Fig. 2e, f). For example, the average ash content of our 602 coal samples was $26.91 \%$ compared to the average ash content of US coal, $14.08 \%$ (ref. 23), but is consistent with recent studies ${ }^{24}$.

Finally, we assessed the oxidation rate (carbon oxidized per carbon content) of the fossil fuels consumed by 15 major industry sectors in
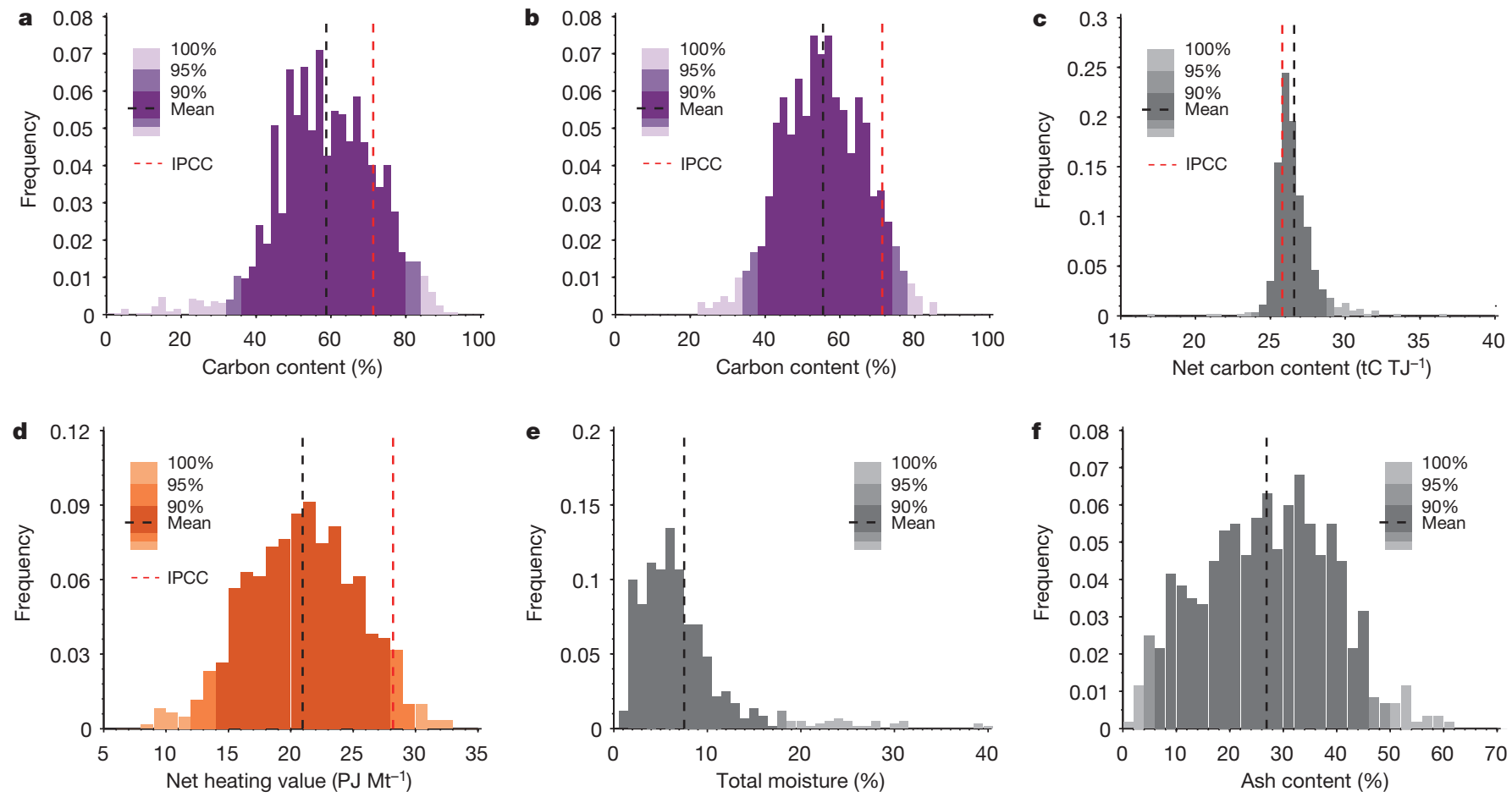

Figure $2 \mid$ Histograms of Chinese coal properties. a, b, Total carbon content of 4,243 coal mines (a) and 602 coal samples (b). Dashed lines show mean, and shading indicates $90 \%$ and $95 \%$ intervals. c, d, Net carbon content (c) and net heating values (d) of the 602 coal samples. Carbon content for coal mines (a) and samples (b) are significantly lower than IPCC values, which is mainly

because of the lower net heating values of China's coal (d); net carbon content is close to the IPCC value (c). e, f, Total moisture (e) and ash content (f) further proved the low quality of China's coal, which in general has high ash content but low carbon content. 
China with 135 different combustion technologies (see Supplementary Data), as analysed by the National Development and Reform Commission (NDRC; ref. 25). We calculate a production-weighted average oxidation rate for coal of $92 \%$, somewhat lower than the IPCC default value of $98 \%$, but generally consistent with China-specific values reported by the NDRC $(94 \%)^{25}$, China's National Communication that reported to UNFCCC $(92 \%)^{8}$, and the estimate from a previous study (on average $93 \%)^{26}$. Our estimates of the oxidation values of oil and natural gas in China ( $98 \%$ and $99 \%$, respectively) are each within $1 \%$ of the IPCC default value.

Combining our revised estimates of carbon content, heating value and oxidation value, we derive new emission factors for coal, natural gas and oil burned in China. The revised emission factors differ from IPCC defaults by $-40 \%,+13 \%$ and $-1 \%$, respectively (Fig. 3 ). In turn, applying these lower emission factors to our revised estimates of energy consumption, our best estimate of Chinese carbon emissions from fossil fuel combustion in 2013 is $2.33 \mathrm{GtC}$ using the carbon content of 4,243 coal mine samples, and $2.31 \mathrm{GtC}$ if the carbon content of 602 coal samples is used. On the basis of the residual scatter of carbon contents from these independent sets of coal samples (Fig. 1), the associated $2 \sigma$ uncertainty related to coal carbon content

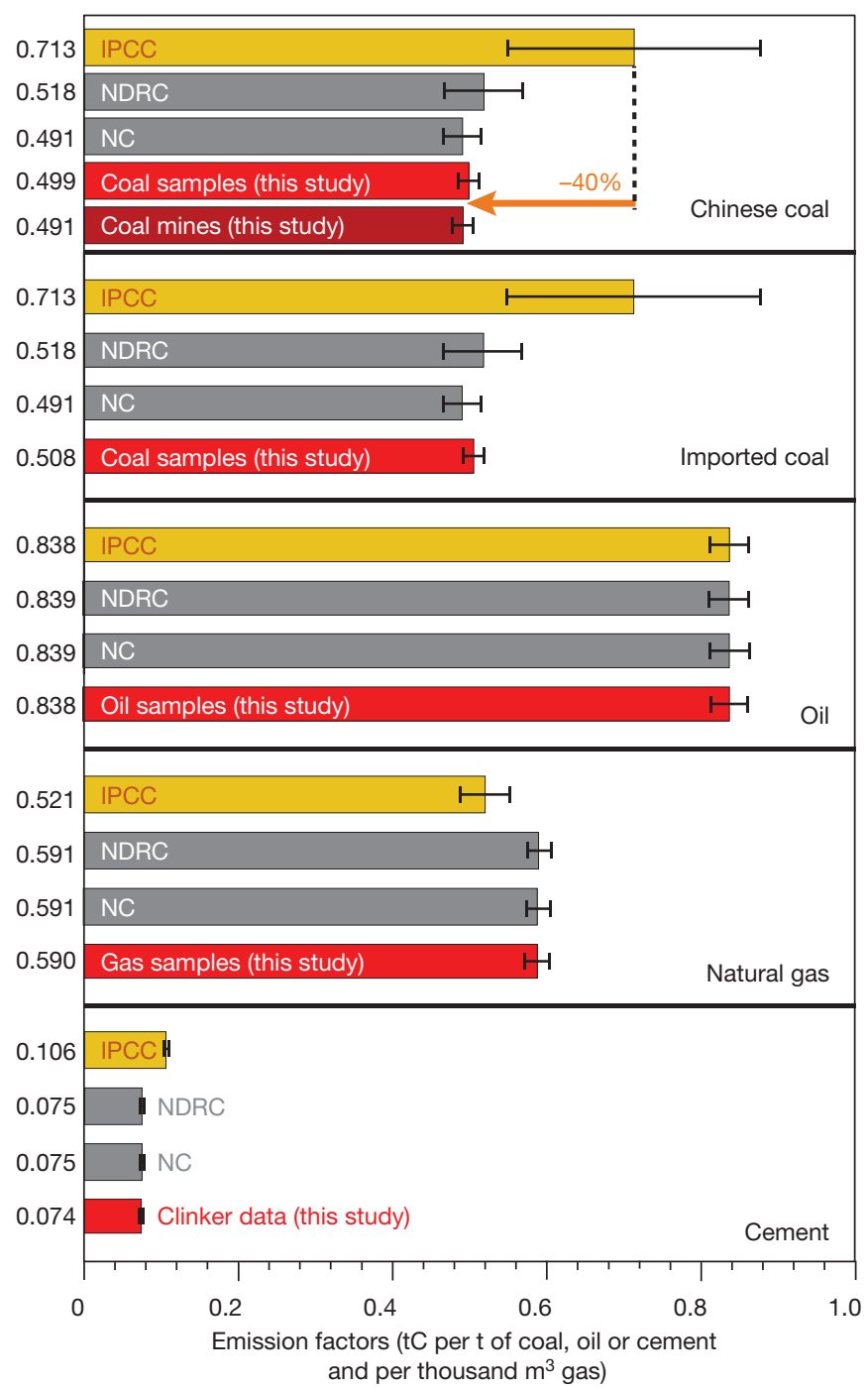

Figure 3 Comparison of emission factors in 2012. IPCC: default value from IPCC guidelines for national emission inventories $(1996,2006)^{7,11}$. NDRC: value reported by the NDRC (ref. 25). NC: China's National Communication, which reported to the UNFCCC (2012 for value in 2005) ${ }^{8}$. All error bars are $2 \sigma$ errors. is of the order of $3 \%$. Additional uncertainty about Chinese emissions is provided by varying the estimates of coal consumed, by $\pm 10 \%$ as evidenced by the range between national and provincial activity data $^{16,19}$. Combining these two numbers gives the $7.3 \%$ uncertainty range of Chinese fossil fuel carbon dioxide emissions.

We also used clinker production data ${ }^{27}$ to recalculate $\mathrm{CO}_{2}$ emissions from cement production (which accounts for roughly $7 \%-9 \%$ of China's total annual emissions in recent years ${ }^{4}$ ). This direct method avoids use of default clinker-to-cement ratios (for example, $75 \%$ and $95 \%$ in the IPCC guidelines ${ }^{7,11}$ ), and results in emissions estimates that are $32 \%-45 \%$ lower than previous estimates $(0.17 \mathrm{GtC}$ in $2012 \mathrm{com}-$ pared to $0.30 \mathrm{GtC}$ reported by the Carbon Dioxide Information Analysis Center (CDIAC) and 0.24 GtC by EDGAR; Extended Data Fig. 4). The clinker-to-cement ratio calculated by clinker production is $58 \%$, or $\sim 23 \%$ lower than the latest IPCC default values. The new, lower estimated cement emissions are consistent with factory-level investigations $^{28}$ and several other recent studies ${ }^{29,30}$.

Together, our revised estimate of fossil fuel and cement emissions in 2013 is $2.49 \mathrm{GtC}(2 \sigma= \pm 7.3 \%)$; the new estimate is $12 \%$ less than the latest inventories China reported to the UNFCCC (1.63 GtC in 2005, $2 \sigma= \pm 8)$ and $14 \%$ less than the estimate by EDGAR version $4.2(2.84$ GtC in 2013, $2 \sigma= \pm 10 \%$ ) (Fig. 4). By $t$-test, our revised estimates of fossil fuel and cement emissions during 2000-2013 are generally lower (at the $90 \%$ level) than estimates by EDGAR $(P=0.016)$ and CDIAC $(P=0.077)$.

Our new estimate represents a substantial revision of annual global carbon emissions, reducing the global emissions in 2013 by $0.35 \mathrm{GtC}$, an amount larger than the reported increase in global emissions between 2012 and 2013 (ref. 31). A systematic reduction of fossil fuel and cement emissions of $0.35 \mathrm{GtC}$ translates into a $15 \%$ smaller land sink when this term is calculated as a residual between anthropogenic carbon emissions, atmosphere carbon growth and the ocean carbon $\sin ^{31}$, and is two times the estimated carbon sink in China's forests $\left(0.18 \mathrm{GtC}^{-1}\right)^{9}$. Thus it implies a considerable revision of the global carbon budget $^{31}$. Over the full period 2000 to 2013, the downward

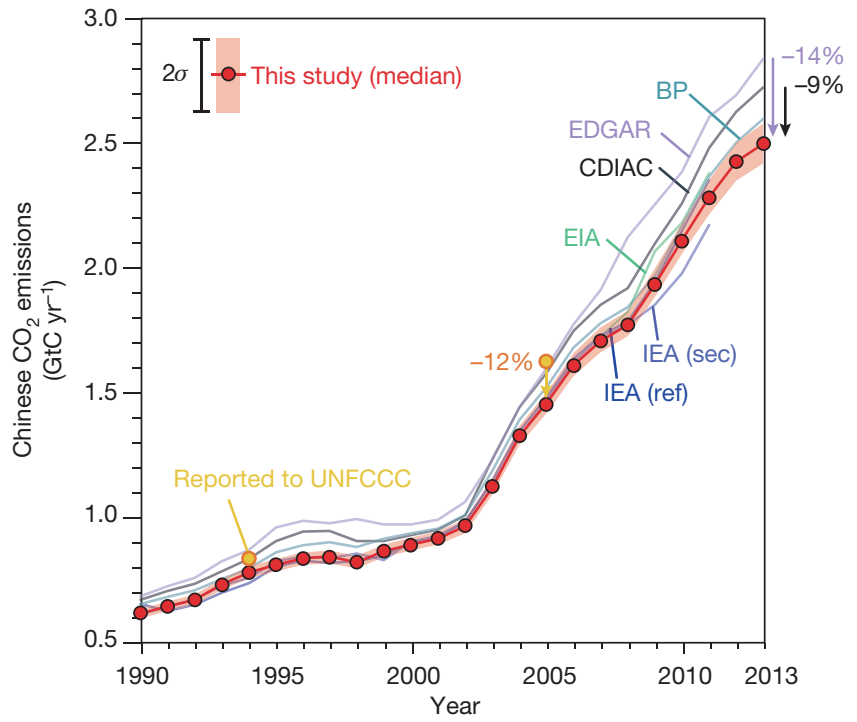

Figure $4 \mid$ Estimates of Chinese $\mathrm{CO}_{2}$ emissions 1990-2013. Total carbon emissions from combustion of fossil fuels and manufacture of cement in China from different sources (International Energy Agency (IEA; sec, sectoral; ref, reference) ${ }^{3}$, Energy Information Administration (EIA; http://www.eia.gov/) and $\mathrm{BP}^{18}$ estimates do not include the emissions from cement production). The yellow dots are the numbers China reported to the UNFCCC in the years 1994 and 2005 (ref. 8). The red-shaded area indicates the 95\% uncertainty range of carbon emissions calculated by this study, assuming the emission factors during the period 1990-2013 are the same as those determined for 2012 in this study. 
revision of cumulative emissions in China by $2.9 \mathrm{GtC}(13 \%)$ is larger than the cumulative forest sink in 1990-2007 $(2.66 \mathrm{GtC})^{9}$ or China's land carbon sink in $2000-2009(2.6 \mathrm{GtC})^{10}$. Depending upon how the remaining quota of cumulative future carbon emissions is shared among nations, a correction of China's current annual emissions by $10 \%$ suggests a $25 \%$ (inertia basis) or $70 \%$ (blended basis) difference in the cumulative future emissions that can be emitted by China under a $2{ }^{\circ} \mathrm{C}$ warming target ${ }^{32}$. Evaluating progress towards national commitments to reduce $\mathrm{CO}_{2}$ emissions depends upon improving the accuracy of annual emissions estimates and reducing related uncertainties ${ }^{33}$.

Online Content Methods, along with any additional Extended Data display items and Source Data, are available in the online version of the paper; references unique to these sections appear only in the online paper.

\section{Received 24 November 2014; accepted 10 June 2015.}

1. Boden, T. A., Marland, G. \& Andres, R. J. Global, Regional, and National Fossil-Fuel $\mathrm{CO}_{2}$ Emissions (Oak Ridge National Laboratory, US Department of Energy, 2013).

2. Liu, Z. et al. A low-carbon road map for China. Nature 500, 143-145 (2013).

3. International Energy Agency. $\mathrm{CO}_{2}$ Emissions from Fuel Combustion (IEA, 2013).

4. Olivier, J. G., Janssens-Maenhout, G. \& Peters, J. A. Trends in Global CO 2 Emissions: 2013 Report (PBL Netherlands Environmental Assessment Agency, 2013).

5. Kurokawa, J. et al. Emissions of air pollutants and greenhouse gases over Asian regions during 2000-2008: Regional Emission inventory in ASia (REAS) version 2. Atmos. Chem. Phys. 13, 11019-11058 (2013).

6. National Bureau of Statistics of China. Chinese Energy Statistics Yearbook (China Statistics Press, 2013)

7. Intergovernmental Panel on Climate Change. 2006 IPCC Guidelines for National Greenhouse Gas Inventories (IPCC, 2006).

8. National Development and Reform Commission. Second National Communication on Climate Change of the People's Republic of China (Department of Climate Change, 2012).

9. Pan, Y. et al. A large and persistent carbon sink in the world's forests. Science $\mathbf{3 3 3}$ 988-993 (2011)

10. Piao, S. et al. The carbon balance of terrestrial ecosystems in China. Nature 458, 1009-1013 (2009)

11. Intergovernmental Panel on Climate Change. Revised 1996 IPCC Guidelines for National Greenhouse Gas Inventories (IPCC, 1997)

12. Gregg, J. S., Andres, R. J. \& Marland, G. China: emissions pattern of the world leader in $\mathrm{CO}_{2}$ emissions from fossil fuel consumption and cement production. Geophys. Res. Lett. 35, L08806 (2008).

13. Andres, R. J., Boden, T. A. \& Higdon, D. A new evaluation of the uncertainty associated with CDIAC estimates of fossil fuel carbon dioxide emission. Tellus B Chem. Phys. Meterol. 66, 23616 (2014).

14. Fridley, D. Inventory of China's Energy-Related $\mathrm{CO}_{2}$ Emissions in 2008 (Lawrence Berkeley National Laboratory, 2011).

15. Andres, R. J. et al. A synthesis of carbon dioxide emissions from fossil-fue combustion. Biogeosciences 9, 1845-1871 (2012)

16. Guan, D., Liu, Z., Geng, Y., Lindner, S. \& Hubacek, K. The gigatonne gap in China's carbon dioxide inventories. Nature Climate Change 2, 672-675 (2012).

17. Sinton, J. E. \& Fridley, D. G. A guide to China's energy statistics. J. Energ. Lit. 8, 22-35 (2002).

18. BP. BP Statistical Review of World Energy 2014 (BP, 2014)

19. Zhao, Y., Nielsen, C. P. \& McElroy, M. B. China's $\mathrm{CO}_{2}$ emissions estimated from the bottom up: recent trends, spatial distributions, and quantification of uncertainties. Atmos. Environ. 59, 214-223 (2012).

20. Reuter, $\mathrm{M}$. et al. Decreasing emissions of $\mathrm{NO}_{x}$ relative to $\mathrm{CO}_{2}$ in East Asia inferred from satellite observations. Nature Geosci. 7, 792-795 (2014).

21. Lin, J.-T. \& McElroy, M. Detection from space of a reduction in anthropogenic emissions of nitrogen oxides during the Chinese economic downturn. Atmos. Chem. Phys. 11, 8171-8188 (2011).
22. National Bureau of Statistics. China Statistical Yearbook 1996-2014 (China Statistics Press, 2014).

23. Hatch, J. R., Bullock, J. H. \& Finkelman, R. B. Chemical Analyses Of Coal, CoalAssociated Rocks And Coal Combustion Products Collected For The National Coal Quality Inventory (USGS, 2006).

24. Zhao, Y., Wang, S., Nielsen, C. P., Li, X. \& Hao, J. Establishment of a database of emission factors for atmospheric pollutants from Chinese coal-fired power plants. Atmos. Environ. 44, 1515-1523 (2010).

25. National Development and Reform Commission. Guidelines for China's Provincial GHG Emission Inventories (NDRC, 2012).

26. Peters, G., Weber, C. \& Liu, J. Construction of Chinese Energy and Emissions Inventory (NTNU, 2006).

27. China Cement Association. China Cement Almanac 2012-2013 (China Building Materials Press, 2014).

28. Shen, L. et al. Factory-level measurements on $\mathrm{CO}_{2}$ emission factors of cement production in China. Renew. Sustain. Energy Rev. 34, 337-349 (2014).

29. Liu, M. et al. Refined estimate of China's $\mathrm{CO}_{2}$ emissions in spatiotemporal distributions. Atmos. Chem. Phys. 13, 10873-10882 (2013).

30. Ke, J., McNeil, M., Price, L., Khanna, N. Z. \& Zhou, N. Estimation of $\mathrm{CO}_{2}$ emissions from China's cement production: methodologies and uncertainties. Energy Policy 57, 172-181 (2013).

31. Le Quéré, C. et al. Global carbon budget 2014. Earth Syst. Sci. Data Discuss. 7, 521-610 (2014).

32. Raupach, M. R. et al. Sharing a quota on cumulative carbon emissions. Nature Clim. Change 4, 873-879 (2014).

33. Liu, Z. et al. Climate policy: Steps to China's carbon peak. Nature 255, 279-781 (2015)

Supplementary Information is available in the online version of the paper.

Acknowledgements This work was supported by the Strategic Priority Research Program "Climate Change: Carbon Budget and Relevant Issues" of the Chinese Academy of Sciences, and by China's National Basic Research Program and National Natural Science Foundation of China (NSFC) funded projects (grants XDA05010109, 2014CB441301, XDA05010110, XDA05010103, XDA05010101, 41328008 and 41222036). Z.L. acknowledges Harvard University Giorgio Ruffolo fellowship and support from Italy's Ministry for Environment, Land and Sea. D.G. acknowledges the Economic and Social Research Council funded project "Dynamics of Green Growth in European and Chinese Cities" (ES/L016028) and the Philip Leverhulme Prize. S.J.D. acknowledges support from the Institute of Applied Ecology, Chinese Academy of Sciences Fellowships for Young International Distinguished Scientists. P.C. and S.P. acknowledge support of the European Research Council Synergy grant ERC-2013-SyG 610028-IMBALANCE-P. R.J.A. and T.A.B. were sponsored by the US Department of Energy, Office of Science, Biological and Environmental Research under US Department of Energy contract DE-AC05-000R22725. J. Lin acknowledges the NSFC (41422502 and 41175127). J. Liu acknowledges the International Science \& Technology Cooperation Program of China (2012DFA91530), the NSFC

(41161140353, 91425303), The Natural Science Foundation of Beijing, China (8151002), the National Program for Support of Top-notch Young Professionals, and Fundamental Research Funds for the Central Universities (TD-JC-2013-2). F.X acknowledges the NSFC (41473076), China CDM Fund $(2013051,2013124)$ and Shenyang Science and Technology Planning (F14-232-6-01, F14-134-9-00). G.P.P. acknowledges funding from the Norwegian Research Council (235523). The authors are grateful to S. Piao, L. Cao and J. Yan for insightful comments.

Author Contributions Z.L. and D.G. designed the paper. Z.L. conceived the research. Z.L. provided the data from 4,243 coal mines. W.W. and J.B. provided the measurement data from 602 coal samples. S.J.D., J.B., O.Z., R.J.A. and T.A.B. provided the reference data. Z.L., D.G., S.J.D., P.C., S.P., J.L., H.Z., C.H., Y.L. and Q.Z. performed the analysis. S.J.D S.P., Z.L., H.Z. and K.F. drew the figures. All authors contributed to writing the paper.

Author Information Reprints and permissions information is available at www.nature.com/reprints. The authors declare no competing financial interests. Readers are welcome to comment on the online version of the paper. Correspondence and requests for materials should be addressed to Z.L. (liuzhu@iae.ac.cn), D.G. (dabo.guan@uea.ac.uk),W.W. (weiwei@sari.ac.cn) or K.H. (hekb@tsinghua.edu.cn). 


\section{METHODS}

Calculation of carbon emissions from fossil fuel combustion and cement production. Carbon emissions are calculated by using activity data, which are expressed as the amount of fossil fuels in physical units used during a production processes (activity data clinker $_{1}$ is the amount of clinker produced) multiplied by the respective emission factor $(\mathrm{EF})$ :

$$
\text { Emission }=\text { activity data } \times \mathrm{EF}
$$

Emissions from cement manufacturing are estimated as:

$$
\text { Emission }_{\text {cement }}=\text { activity data } \text { clinker } \times \mathrm{EF}_{\text {clinker }}
$$

If data on sectorial and fuel-specific activity data and $\mathrm{EF}$ are available, total emission can be calculated by:

$$
\text { Emission }=\sum \sum \sum\left(\text { activity data } a_{i, j, k} \times \mathrm{EF}_{i, j, k}\right)
$$

where $i$ is an index for fuel types, $j$ for sectors, and $k$ for technology type. Activity data are measured in physical units (tonnes of fuel expressed as $t$ fuel).

$\mathrm{EF}$ can be further separated into net heating value of each fuel $v$, the energy obtained per unit of fuel (TJ per t fuel), carbon content $c\left(\mathrm{tC} \mathrm{TJ}^{-1}\right.$ fuel) and oxidization rate $o$ (in \%, the fraction of fuel oxidized during combustion and emitted to the atmosphere). The values of $v, c$ and $o$ are specific for fuel type, sector and technology:

$$
\text { Emission }=\sum \sum \sum\left(\text { activity data }_{i, j, k} \times v_{i, j, k} \times c_{i, j, k} \times o_{i, j, k}\right)
$$

For the coal extracted in China (for example, for the 4,243 coal mines analysed in this study), net heating $v$ and carbon content $c$ values are not directly available, and a more straightforward emission estimate for coal emissions can be obtained using the mass carbon content $\left(C_{\mathrm{ar}}\right.$ in tC per t fuel) of fuels, defined by $C_{\mathrm{ar}}=c \times v$ so that the total emission can be calculated as:

$$
\text { Emission }=\sum \sum \sum\left(\text { activity data } a_{i, j, k} \times C_{\mathrm{ar}_{i, j, k}} \times o_{i, j, k}\right)
$$

Apparent energy consumption calculation. The activity data can be directly extracted as the final energy consumption from energy statistics, or estimated based on the mass balance of energy, the so-called apparent energy consumption estimation:

Apparent energy consumption $=$ domestic production + imports - exports \pm change in stocks - non-energy use of fuels

Calculation of carbon emission from cement production. The carbon emission from cement production is due to the production of clinker, which is the major component of cement. When clinker is produced from raw materials, the calcination process of calcium carbonate $\left(\mathrm{CaCO}_{3}\right)$ and cement kiln dust $(\mathrm{CKD})$ releases $\mathrm{CO}_{2}: \mathrm{CaCO}_{3} \rightarrow \mathrm{CaO}+\mathrm{CO}_{2}$. The amount of emission can be calculated from the molar masses of $\mathrm{CaO}\left(55.68 \mathrm{~g} \mathrm{~mole}^{-1}\right)$ and carbon $\left(12 \mathrm{~g} \mathrm{~mole}^{-1}\right)$ and the proportion of their masses in clinker production. Furthermore, the emission associated with CKD that is not recycled to the kiln is calculated using the CKD correction factor, $\mathrm{CF}_{\mathrm{cdk}}$.

Carbon emission from cement production can be calculated the by clinker emission factor $\left(\mathrm{EF}_{\text {clinker }}\right)$ and clinker production.

$$
\begin{aligned}
\text { Emission }_{\text {cement }} & =\text { activity data } \\
\mathrm{EF}_{\text {clinker }} \times \mathrm{EF}_{\text {clinker }} & =\mathrm{EFCaO} \times\left(1+\mathrm{CF}_{\mathrm{cdk}}\right)
\end{aligned}
$$

$\mathrm{EF} \mathrm{CaO}_{\text {clinker }}=$ fraction $\mathrm{CaO} \times(12 / 55.68)=$ fraction $\mathrm{CaO} \times 0.2155$

Fraction $\mathrm{CaO}$ is the mass proportion of $\mathrm{CaO}$ per unit clinker (in \%). $\mathrm{EF} \mathrm{CaO}_{\text {clinker }}$ is the mass of total carbon emission released as $\mathrm{CaO}$ per unit of clinker (unit: $\mathrm{tC}$ per $t$ clinker). $\mathrm{CF}_{\mathrm{cdk}}$ is the $\mathrm{CKD}$ correction factor (in \%). $\mathrm{EF}_{\text {clinker }}$ is the mass of total carbon emission per unit of clinker ( $\mathrm{tC}$ per $\mathrm{t}$ clinker)

Clinker is the major component of cement. However, data on clinker production is less widely reported than that of cement production. Where data about clinker production are not available, the clinker-to-cement ratio $R_{\text {clinker-cement }}$ (in \%) can be used to estimate the cement emission factor $\left(\mathrm{EF}_{\text {cement }}\right)$ and to further estimate the emission based on cement production.

$$
\begin{gathered}
R_{\text {clinker-cement }}=\text { activity data } \text { clinker }_{\text {activity data }} \text { cement } \\
\mathrm{EF}_{\text {cement }}=R_{\text {cement-clinker }} \times \mathrm{EF}_{\text {clinker }} \\
\text { Emission }_{\text {cement }}=\mathrm{EF}_{\text {cement }} \times \text { activity data }
\end{gathered}
$$

The IPCC default Fraction $\mathrm{CaO}$ (clinker) is $64.6 \%$, and the fraction $\mathrm{CaO}$ (cement) is $63.5 \%$; thus, the IPCC default $\mathrm{EF}_{\text {clinker }}$ is 0.1384 ( $\mathrm{tC}$ per $\mathrm{t}$ clinker). In the IPCC 1996 guidelines, the clinker-to-cement ratio is $95 \%$, which assumes that most cement is Portland cement and that the corresponding default $\mathrm{EF}_{\text {cement }}$ is 0.1360 (tC per t clinker). In the IPCC 2006 guidelines, the clinker-to-cement ratio is $75 \%$ when no direct clinker production data are available, and the corresponding default $\mathrm{EF}_{\text {cement }}$ is 0.1065 (tC per t clinker). In this study, the clinker-to-cement ratio is calculated using clinker production statistics and cement production statistics. The cement production and clinker production statistics are listed in Supplementary Information.

It should be noted that the non-energy use of fossil fuels and other industrial processes such as ammonia production, lime production and steel production will also produce carbon emissions. To be consistent with the scope of the international data set we are comparing, those emissions are not included in this study. On the basis of a previous study the total emissions of these non-energy fuel use and industry processes was equivalent to $1.2 \%$ of China's emissions from fossil combustion in 2008 (ref. 14).

The uncertainty range of China's emission estimates. We conduct analysis to show the uncertainty range of China's emission estimates based on emission factors (EFs) reported in the literature. We collected 12 sets of EF data for fossil fuel combustion from the six following official sources: IPCC $(1996,2006)^{7,11}$, China National Development and Reform Commission (NDRC) $)^{34}$, UN Statistics $(\mathrm{UN})^{35}$, China National Communication on Climate Change (NC) ${ }^{8}$, China National Bureau of Statistics (NBS) ${ }^{22}$ and Multi-resolution Emission Inventory for China (MEIC; http://www.meicmodel.org). There are three sets of EFs in the NDRC data, corresponding to three tiers of fuel classifications, four sets in NC and two sets in UN. We combined these 12 sets of EFs with two sets of energy statistics derived from national and provincial data ${ }^{6,36}$. This yielded 24 possible inventories for China's carbon emissions of fossil fuel combustion for 1997-2012 (Extended Data Table 1). The underlying data used in the commonly used data sets (IEA, CDIAC, BP, EDGAR) is either listed in this data assembly (NBS and IPCC) or not publically available.

The mean value of 24 possible inventories is $2,523 \mathrm{MtC}$ in 2012 , and the standard deviation is $376 \mathrm{MtC}(15 \%)$; the detailed data are listed in the Extended Data Table 1 . The $2 \sigma$ standard deviation range suggested by 24 possible inventories is $30 \%$, which is larger than the reported range of $10 \%$ by current emission data sets such as EDGAR.

A Monte Carlo (Extended Data Fig. 1) approach was adopted to assess the distribution range of the emissions by assuming that all reported EF values have the same probability (values have been randomly selected with equal probabilities and calculated for 100,000 times). The mean value of the 24 members' ensemble is $2.43 \mathrm{GtC}$ in 2012 ( $95 \%$ confidence interval is $+20 \%,-11 \%$ and maximumminimum range of $+27 \%,-15 \%)$. The uncertainty is attributed to the activity data (about $40 \%$ of total uncertainty) and EF (60\%). The variability of EF for coal dominates the total uncertainty ( $55 \%$ for total uncertainty and $90 \%$ for the uncertainty by EF), whereas the EF for other fuels are more comparable. Different $\mathrm{EF}$ values for coal mainly reflect variation in $v$ and hence $C_{\mathrm{ar}}\left(C_{\mathrm{ar}}=v \times \mathrm{c}\right)$ values, whereas the variation of $c$ and $o$ are comparatively smaller (less than 10\%).

The distribution range of the emissions is listed in Extended Data Fig. 1.

We assumed the equal possibility for various EFs when conducting the Monte Carlo analysis; this will expand the uncertainty range. However, both the standard deviation of 24 possible inventories and the Monte Carlo analysis show a significant uncertainty range, implying the considerable system error of the emission estimates by using reported EFs; thus it is critical to perform emission estimates based on a measurement-based EF.

Apparent consumption calculation. We adopted the 'apparent consumption' approach to recalculate China's energy consumption. The apparent energy consumption is the mass balance of fuels produced domestically for energy production, trade, international fuelling and change in stocks:

Apparent energy consumption $=$ domestic production + imports - exports

$$
\pm \text { change in stocks - non-energy use of fuels }
$$

The calculated apparent energy consumption is usually different from the reported energy consumption in China. For example, our recalculated energy consumption is higher ( $17 \%$ for coal, $2 \%$ for oil and $3 \%$ for gas) than the national reported energy consumption for 2013.

We believe the resulting estimates of energy consumption to be more accurate than both national and provincial energy statistics, because of the following reasons.

First, national energy statistics may be biased ${ }^{16,37,38}$ because of underreported fuel use in boilers from small factories and workshops ${ }^{17,37,38}$. In addition, the 
adjustment of national statistics by the Chinese government has been discussed in the literature ${ }^{39-41}$.

Second, provincial energy statistics are also not reliable because of the considerable inconsistencies in provincial aggregated final-consumption energy statistics. When comparing energy consumption with total available energy supply (production plus imports and changes in stocks) in provincial statistics for 2012, coal and oil show differences of $0.25 \mathrm{Gt}$ coal and $81 \mathrm{Mt}$ oil ${ }^{6,22}$, respectively. In addition, after removing international trade, the amount of exported and imported coal within all provinces should be equal to each other, whereas, in fact, we found an unexplained mismatch of $0.37 \mathrm{Gt}$ coal in provincial aggregated energy statistics, equal to $21 \%$ of total domestically traded coal.

Third, the apparent energy consumption is based on production and trade statistics. Chinese data on fuel production and trade statistics are more reliable and consistent than data on final energy consumption. After many years of policies to reduce or close private coal mines, $97 \%$ of the coal production in China $3.40 \mathrm{Gt}$ coal in 2011) is from government-owned companies (including central and local governments) that keep good records of the mass of coal extracted ${ }^{42,43}$. This reliability is supported by the fact that national and provincial statistics on coal production differed by only $10 \%$ in 2012 (refs 6,22 ), while the same sources reported coal consumption rates that differed by $37 \%$ (3.19 Gt for national data versus $4.36 \mathrm{Gt}$ for provincial data). Moreover, coal production and trade data are consistently released earlier than coal consumption data, suggesting that the production data are the original data and therefore less prone to 'adjustment' for political or other proposes. Finally, trade data have also been monitored internationally, so the numbers can be verified by different nations.

Fourth, compared with the final energy consumption approach that involves 20 kinds of primary and secondary energy products, the apparent consumption approach is much simpler: it considers only three primary fuel types (raw coal, crude oil and natural gas) in order to avoid accounting errors due to energy consumed during fuel processing (for example, mass loss in coal washing and coking).

Fifth, the apparent energy consumption approach uses energy production data, which avoids having to deal with uncertain estimations of the mix of different coal types used by each final consumption category. When considering the variation of EFs for different fuel types and sectors, analysis of the sources of uncertainty is more complex. It is difficult to assess specific coal-burning EFs for a myriad of small consumers, and to scale these data up to the national level. Large energy consumers such as power plants continuously mix coal from different sources, which also makes it very difficult to assess national consumption-weighted average EF (weighted by share of different kinds and quality of coal consumed) from a consumption point of view. In contrast, production data can provide the national production-weighted average EF, and thus the national consumption-weighted average EF can be calculated by excluding the coal used for exports, non-energy use and stock changes.

Sixth, the apparent consumption approach allows us to track imported and domestically produced fuels, so that a different $\mathrm{EF}$ can be applied.

Between 1997 and 2012, the calculated apparent energy consumption was 10\% greater (14\% for 2012$)$ than the one reported in national statistics and $4 \%$ lower than provincial statistics (Extended Data Fig. 2). The growth rate of apparent energy consumption is consistent with the growth rate of industrial productions (Extended Data Fig. 5).

Sample selection. China's coal resources are mainly concentrated in 100 major coal mine areas from 24 coal mine bases, and there are about 4,000 stable coal mines among these $100 \mathrm{coal}$ mine areas that record coal production. The location of coal sampling is consistent with the distribution of coal mines (Extended Data Fig. 3).

By collecting the coal samples, the following principles are adopted.

First, the sampling spot is based on coal seams under production in one coal mine district, because the properties of coal from within a coal seam are almost the same. It is guaranteed that at least one sample is collected from each coal seam in one coal mine district.

Second, every coal mine area is sampled, so the 602 samples are across 100 mine areas that cover the majority of the nation's coal production.

Third, there are at least three samples for each coal mine with a production over 5 million tonnes.

Fourth, in the same coal mine district, coal mines with high production are selected preferentially.

Fifth, for sampling within a location, if the samples are collected from a coal pile, they should be collected from at least three different coal piles. If the samples are collected from a conveyor belt, they should be collected three times with several hour intervals from each other. All these three-times-collected samples are merged together and considered as one sample data point (in total 602 sample data points) for further analysis. All samples are stored in sealed plastic bags for further analysis. Sample analysis. For the sample measurements, we measured the air dry moisture, total moisture, net heating value, and the ash, carbon, hydrogen, nitrogen and total sulfur content. Carbon, hydrogen, nitrogen and total sulfur are determined by combustion using an Elementar elemental analyser. Coal samples are weighed into a tin capsule and burned in a tube furnace at $1,350^{\circ} \mathrm{C}$. Carbon dioxide, water, nitrogen dioxide and sulfur oxide are released from the samples and measured by a thermal conductive detector (TCD). Two parallel samples were tested together each time. The analysis is performed based on ISO standards:

Measurement process (ISO 18283:2006: Hard coal and coke-Manual sampling).

Air dry moisture (ISO 11722:2013: Solid mineral fuels. Hard coal. Determination of moisture in the general analysis test sample by drying in nitrogen).

The total moisture (ISO 589:2008: Hard coal. Determination of total moisture).

Carbon, hydrogen and nitrogen contents (ISO 625:1996: Solid mineral fuels. Determination of carbon and hydrogen. Liebig method; ISO 29541:2010: Solid mineral fuels. Determination of total carbon, hydrogen and nitrogen content. Instrumental method).

Ash content and volatile matter (ISO 11722:2013: Solid mineral fuels. Hard coal. Determination of moisture in the general analysis test sample by drying in nitrogen; ISO 1171:1997: Solid mineral fuels. Determination of ash; and ISO 562:2010: Hard coal and coke. Determination of volatile matter)

The net calorific value (ISO 1928:2009: Solid mineral fuels. Determination of gross calorific value by the bomb calorimetric method and calculation of net calorific value).

Total sulfur contents (ISO 334:2013: Solid mineral fuels. Determination of total sulphur. Eschka method).

34. National Development and Reform Commission. The People's Republic of China National Greenhouse Gas Inventory (China Environmental Science Press, 2007).

35. The United Nations. Energy Statistics Database (United Nations Publications, 2010).

36. Fridley, E. D. China Energy Databook—User Guide and Documentation, Version 7.0 (Lawrence Berkeley National Laboratory, 2008).

37. Sinton, J. E. Accuracy and reliability of China's energy statistics. China Econ. Rev. 12, 373-383 (2001).

38. Marland, G. Emissions accounting: China's uncertain $\mathrm{CO}_{2}$ emissions. Nature Clim Change 2, 645-646 (2012).

39. Liu, J. \& Yang, H. China fights against statistical corruption. Science $\mathbf{3 2 5}, 675$ (2009).

40. Holz, C. A. The quality of China's GDP statistics. China Econ. Rev. 30, 309-338 (2014).

41. Rawski, T. G. What is happening to China's GDP statistics? China Econ. Rev. 12 347-354 (2001)

42. Tu, J. Industrial Organisation of the Chinese Coal Industry (Freeman Spogli Institute for International Studies, 2011).

43. State Administration of Coal Mine Safety. China Coal Industry Yearbook (Coal Information Research Institute, 2013). 


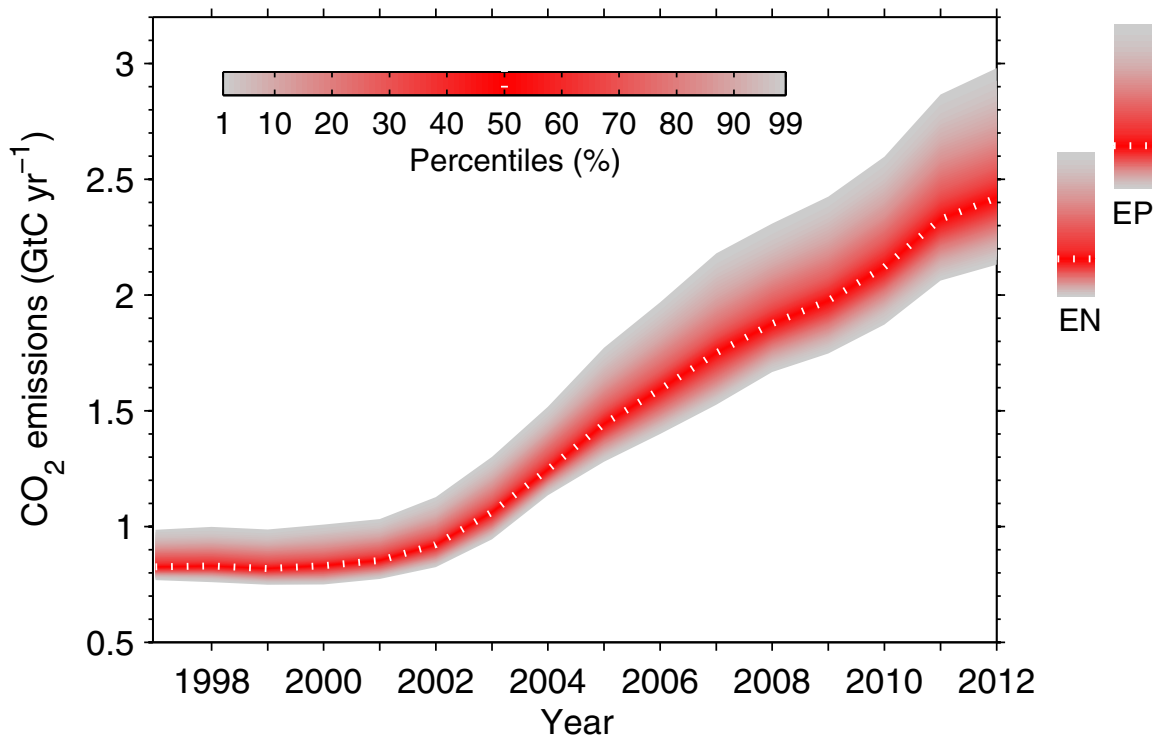

Extended Data Figure 1 | Uncertainty distribution of Chinese $\mathrm{CO}_{2}$ emissions 1997-2012. Monte Carlo simulations of the Chinese carbon emissions based on a blended activity data set where national and provincial data are assigned equal probabilities $(n=100,000)$. Chinese carbon emissions based on national energy activity data (EN) and provincial activity energy data (EP) in 2012 are shown on the right bar. 


\section{RESEARCH LETTER}

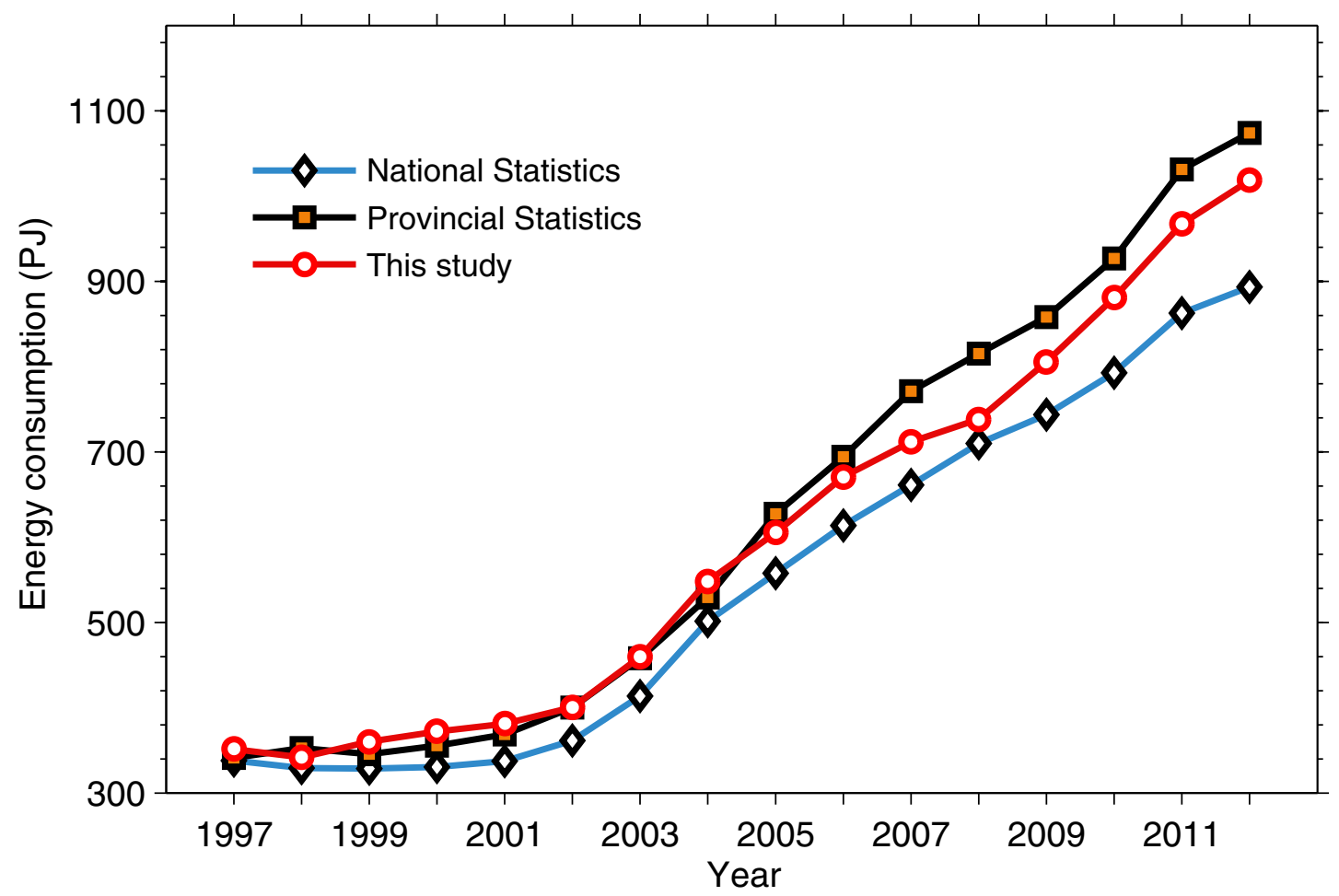

Extended Data Figure $2 \mid$ Total fossil fuel energy consumption based upon national statistics, provincial statistics and calculations in this study. 


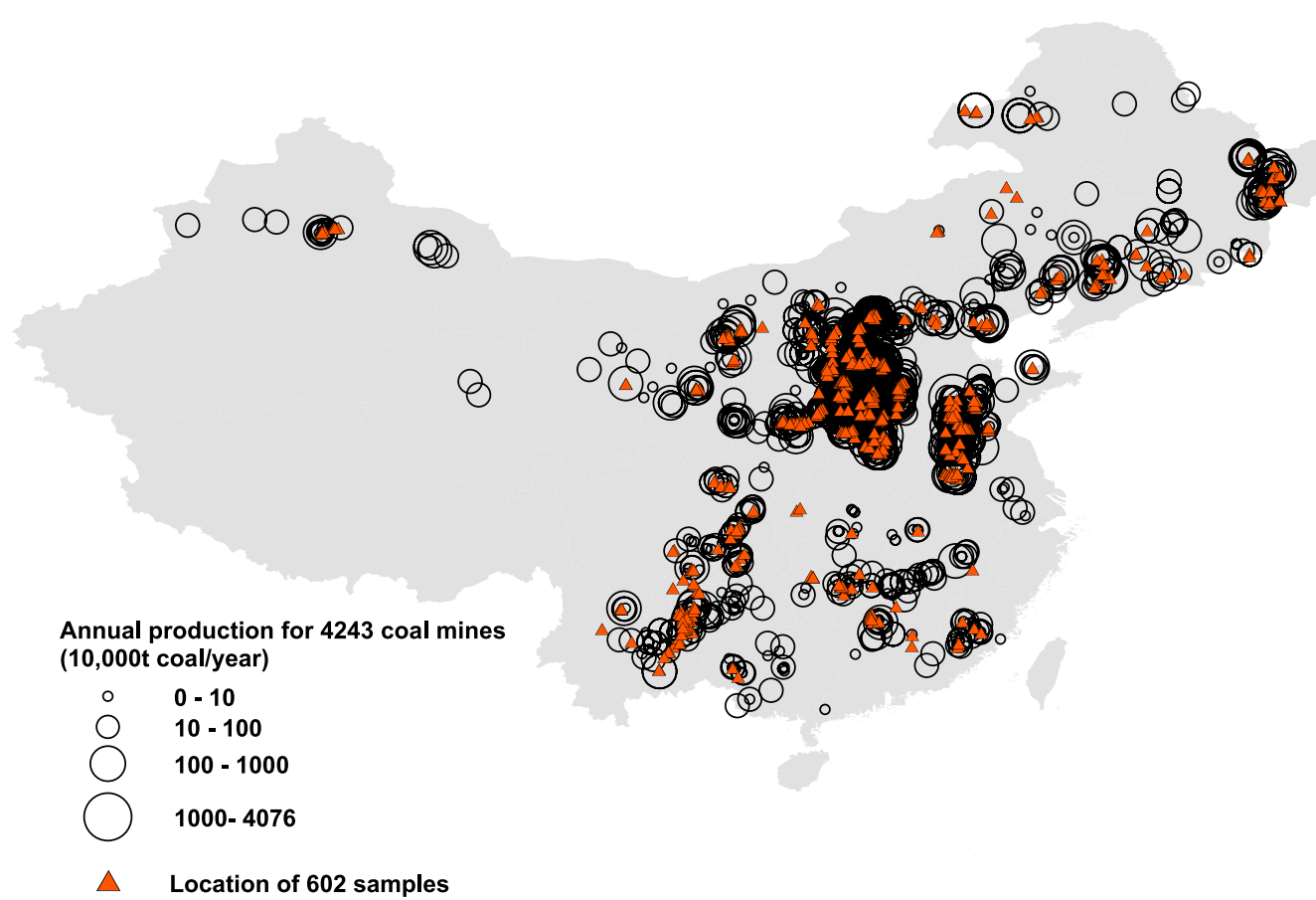

Extended Data Figure $3 \mid$ Location of 4,243 coal mines with annual production and 602 coal samples. The coal samples and mines are consistent with spatial distribution. 


\section{RESEARCH LETTER}

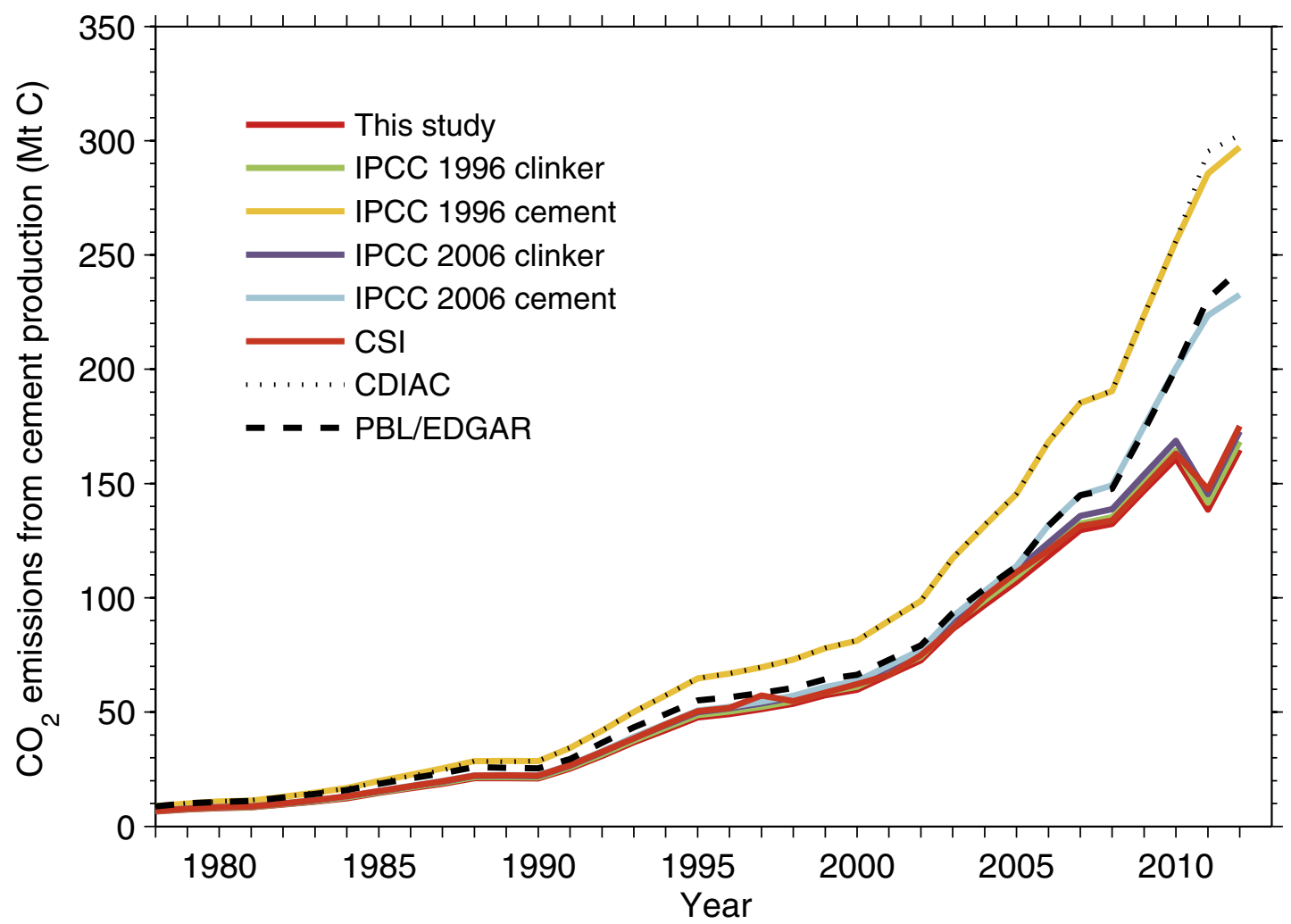

Extended Data Figure $4 \mid$ Emission estimates of China's cement production by different sources. 


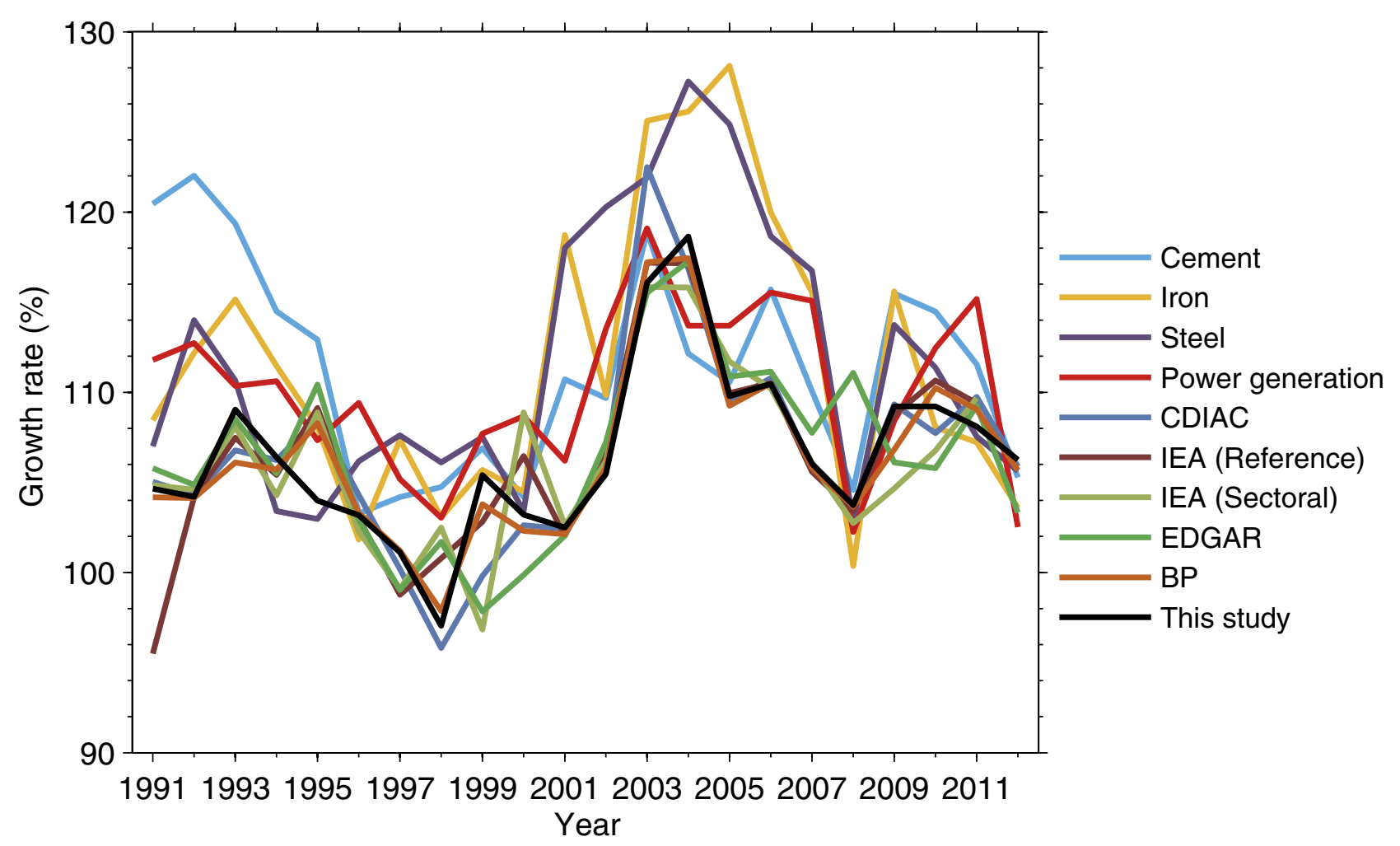

Extended Data Figure 5 | Growth rate of carbon emissions, based upon BP, EGDAR, IEA and calculations in this study, and industrial products. Industrial products comprise the production of cement, iron, steel and power

generation. The emission trends calculated in this study are consistent with the trends of industrial production. 


\section{RESEARCH LETTER}

Extended Data Table 1 | Twenty-four emission inventories of fossil fuel combustion based on reported emission factors and fuel inventories in China.

\begin{tabular}{|c|c|c|c|c|c|c|c|c|c|c|c|c|c|c|c|c|}
\hline Unit: MtC & 1997 & 1998 & 1999 & 2000 & 2001 & 2002 & 2003 & 2004 & 2005 & 2006 & 2007 & 2008 & 2009 & 2010 & 2011 & 2012 \\
\hline IPCC EP & 1081 & 1113 & 1087 & 1109 & 1153 & 1256 & 1438 & 1662 & 1969 & 2180 & 2432 & 2573 & 2707 & 2964 & 3251 & 3379 \\
\hline IPCC EN & 1062 & 1028 & 1017 & 1016 & 1034 & 1106 & 1286 & 1543 & 1722 & 1892 & 2036 & 2220 & 2332 & 2442 & 2700 & 2783 \\
\hline NBS EP & 837 & 862 & 846 & 868 & 902 & 983 & 1127 & 1303 & 1548 & 1716 & 1912 & 2021 & 2126 & 2319 & 2561 & 2664 \\
\hline NBS EN & 827 & 805 & 800 & 803 & 819 & 879 & 1015 & 1228 & 1375 & 1514 & 1632 & 1760 & 1847 & 1933 & 2144 & 2213 \\
\hline NDRC tier $1 \mathrm{EN}$ & 840 & 817 & 813 & 816 & 832 & 891 & 1037 & 1251 & 1400 & 1542 & 1662 & 1802 & 1893 & 1981 & 2196 & 2266 \\
\hline NDRC tier $1 \mathrm{EP}$ & 851 & 877 & 861 & 881 & 918 & 1000 & 1148 & 1330 & 1580 & 1753 & 1958 & 2070 & 2181 & 2392 & 2626 & 2737 \\
\hline NDRC tier 2 EP & 841 & 868 & 849 & 869 & 903 & 984 & 1128 & 1305 & 1550 & 1718 & 1918 & 2030 & 2139 & 2346 & 2573 & 2685 \\
\hline NDRC tier $2 \mathrm{EN}$ & 829 & 805 & 800 & 802 & 817 & 874 & 1016 & 1225 & 1370 & 1506 & 1622 & 1762 & 1850 & 1934 & 2143 & 2212 \\
\hline NDRC tier 3 EP & 850 & 879 & 858 & 879 & 910 & 995 & 1137 & 1319 & 1555 & 1723 & 1924 & 2037 & 2137 & 2340 & 2564 & 2675 \\
\hline NDRC tier $3 \mathrm{EN}$ & 837 & 816 & 806 & 808 & 821 & 880 & 1019 & 1236 & 1370 & 1505 & 1620 & 1763 & 1843 & 1926 & 2133 & 2201 \\
\hline NC 1994 EN & 768 & 750 & 746 & 751 & 766 & 822 & 953 & 1151 & 1294 & 1427 & 1538 & 1656 & 1737 & 1819 & 2017 & 2084 \\
\hline NC 1994 EP & 774 & 798 & 784 & 805 & 838 & 913 & 1049 & 1213 & 1446 & 1603 & 1789 & 1892 & 1992 & 2178 & 2403 & 2504 \\
\hline $\mathrm{NC} 2005$ tier $1 \mathrm{EN}$ & 819 & 797 & 790 & 791 & 805 & 860 & 999 & 1206 & 1348 & 1481 & 1594 & 1734 & 1821 & 1903 & 2107 & 2174 \\
\hline NC 2005 tier 1 EP & 831 & 858 & 840 & 859 & 892 & 970 & 1111 & 1283 & 1529 & 1694 & 1891 & 2003 & 2111 & 2313 & 2535 & 2646 \\
\hline NC 2005 tier $2 \mathrm{EN}$ & 816 & 791 & 784 & 783 & 796 & 849 & 985 & 1189 & 1330 & 1459 & 1570 & 1711 & 1796 & 1876 & 2075 & 2141 \\
\hline NC 2005 tier 2 EP & 828 & 856 & 836 & 854 & 885 & 962 & 1100 & 1270 & 1513 & 1675 & 1870 & 1981 & 2090 & 2288 & 2505 & 2615 \\
\hline NC 2005 tier $3 \mathrm{EN}$ & 817 & 794 & 785 & 787 & 799 & 856 & 991 & 1199 & 1331 & 1462 & 1573 & 1713 & 1791 & 1872 & 2072 & 2138 \\
\hline NC 2005 tier 3 EP & 829 & 859 & 837 & 857 & 887 & 969 & 1106 & 1280 & 1513 & 1675 & 1870 & 1981 & 2080 & 2278 & 2495 & 2604 \\
\hline MEIC EN & 792 & 770 & 765 & 768 & 783 & 838 & 968 & 1171 & 1309 & 1440 & 1550 & 1672 & 1754 & 1834 & 2032 & 2099 \\
\hline MEIC EP & 802 & 829 & 810 & 832 & 862 & 938 & 1074 & 1241 & 1475 & 1633 & 1817 & 1923 & 2024 & 2204 & 2437 & 2537 \\
\hline $\mathrm{UN}$ average EN & 1103 & 1063 & 1051 & 1048 & 1064 & 1134 & 1319 & 1575 & 1737 & 1895 & 2031 & 2258 & 2372 & 2490 & 2740 & 2818 \\
\hline UN average EP & 1126 & 1160 & 1134 & 1152 & 1200 & 1305 & 1487 & 1725 & 2042 & 2257 & 2518 & 2663 & 2804 & 3108 & 3353 & 3483 \\
\hline UN China EN & 843 & 814 & 808 & 809 & 822 & 876 & 1014 & 1215 & 1342 & 1464 & 1567 & 1747 & 1836 & 1929 & 2124 & 2186 \\
\hline UN China EP & 856 & 883 & 867 & 881 & 921 & 1001 & 1140 & 1328 & 1577 & 1745 & 1949 & 2061 & 2175 & 2430 & 2596 & 2707 \\
\hline Standard deviation & 105 & 109 & 105 & 107 & 113 & 126 & 142 & 155 & 196 & 219 & 260 & 265 & 280 & 339 & 357 & 376 \\
\hline Average Value & 869 & 870 & 857 & 868 & 893 & 964 & 1110 & 1310 & 1509 & 1665 & 1827 & 1960 & 2060 & 2212 & 2432 & 2523 \\
\hline
\end{tabular}

